\title{
Entrevista a Marika Vila
}

En esta entrevista, la filóloga y artista gráfica Marika Vila analiza la presencia femenina en el discurso del cómic español, contrastándola con su representación en el discurso misógino y homófobo que ha dominado el medio desde sus orígenes. Su trabajo de investigación resalta las transformaciones de la narrativa gráfica española desde los años de la Transición - cuando, con el advenimiento de la democracia, se asiste al nacimiento del cómic de autor y al Boom del cómic para adultos - hasta la época actual en la que se aprecia un gran surgimiento de obras de autoría femenina. Asimismo, gracias a un trabajo de investigación de largo recorrido, Vila recupera la visibilidad y resistencia de las autoras pioneras. A partir de las preguntas de Marina Bettaglio, Trujillo revisa el pasado del cómic español desde una perspectiva de género para destacar la necesidad de rescatar el trabajo de las creadoras y entender su aporte a lo largo de su historia.

In this interview, graphic artist and philologist Marika Vila analyzes the presence of women in Spanish comics against the backdrop of the often misogynistic and homophobic discourse that has characterized this artistic medium since its origins. Drawing upon her academic research, Marika Vila underlines the transformations of Spanish graphic narratives from the Transition period-when the advent of democracy coincided with a boom in adult comics and cómics de autor-to the present, when it is possible to appreciate a noticeable rise in women-authored graphic novels. Moreover, thanks to her far-reaching research, she recuperates the visibility and resistance of the women who were pioneers of the ninth art. In dialogue with Marina Bettaglio, she revisits the history of Spanish comics with a gender perspective in order to highlight the need to recover the work of female creators and to understand their contributions.

MARINA BETTAGLIO: ¿Qué factores han incidido en la proliferación súbita de nombres y temas femeninos en el cómic español que se experimenta hoy en día?

MARIKA VILA: El resultado de una nueva y cada vez más sólida visibilidad mediática para las mujeres en el cómic español debe leerse como fruto de un trabajo de largo recorrido llevado a cabo por las luchas feministas de sus

REVISTA CANADIENSE DE ESTUDIOS HISPÁNICOS 43.I (OTOÑO 2OI8) 
antecesoras durante el siglo XX, desde los orígenes del cómic. Sin una larga lucha oscura y constante, este fenómeno no habría sido posible. Debe valorarse, pues, en su justa importancia, sin descuidar darle la profundidad debida, ya que, nada crece ni se fundamenta sin raíces. Sin ellas, todo avance retorna al ostracismo como resto efímero de los combustibles que agota el consumo. Recuperar el discurso de las autoras pioneras que podemos encontrar en todas las épocas trabajando en absoluta minoría para insertar su voz en el discurso masculino dominante en el cómic español es importante para descubrir las nuevas formas de subjetividad en su grito y religar el hilo que une a Lola Anglada con Ana Miralles, a Núria Pompeia con Flavita Banana, a Marika Vila con Laura Pérez Vernetti y con la vía experimental de las diversas iniciativas que definen a las nuevas voces en el diálogo artístico. Reforzar su continuidad pondrá fin al olvido y la invisibilidad.

Las mujeres del siglo XXI empiezan a traspasar masivamente los límites del silencio al mismo tiempo que los medios empiezan a cambiar el enfoque de sus publicaciones sobre la temática de género, lo cual indica que un nuevo paradigma está tomando cuerpo. Ya hace algún tiempo que las mujeres tanto en España como en otros países occidentales están logrando cambiar su relación con la comunicación y sus medios pero es especialmente destacable el momento actual en la península ibérica, marcado por el éxito mediático del movimiento \#metoo, por el clamor popular contra el maltrato y la pederastia y por la espectacular plasmación de las voces otras $^{2}$ en las imágenes del 8 de marzo de $2018.3^{3}$ Todo ello ha multiplicado el eco de las reivindicaciones feministas en el mundo occidental, creando tendencia y colocando como tema candente en las agendas editoriales, tanto sus demandas como la presencia de sus voces creadoras. Este fenómeno, que afecta a todos los ámbitos del espacio público, está transformando el panorama.

MARINA BETTAGLIO: Al final de tu ensayo Derrumbando estereotipos. La subjetividad femenina en el cómic, publicado en ocasión de la homónima exposición que tuvo lugar en el marco de la Semana Negra de Guijón 20r8, señalas que: "podemos decir que hay cambio, que está vibrando la voz de las autoras y se perfilan nuevos escenarios menos tópicos que empiezan a reflejar mejor las modificaciones sociales, pero lo hacen en pequeños espacios, todo esto sucede hoy sin que su abundante aparición emergente aún con el avance que ello significa - se traduzca en la liberación del lenguaje porque, más allá de continuar conquistando espacios de visibilidad, la búsqueda de un equilibrio aún está bastante lejos de finalizar" 
(62). Parece que vivimos una situación única en cuanto a la presencia de las mujeres en el noveno arte. ¿Podrías profundizar esta reflexión?

MARIKA VILA: En España, después de años de lucha contra la marginalidad y el silencio en el espacio público, donde únicamente la voz androcéntrica y patriarcal de lo masculino ha construido los límites de la realidad sociocultural, moral y artística a su medida, parece que las diversas voces de los feminismos están viviendo un romance con los medios de comunicación, con las artes y la cultura, y con sus portavoces que por fin las empiezan a rondar. Más allá de las defensas que el amor romántico genera en la experiencia de las mujeres, y aun concediendo en dicho romance el espacio usado por la moda, el resultado no es ajeno a la constancia del trabajo resistente en las creadoras. Los nombres femeninos conocen bien la fluctuación de la moda entre el florido descubrimiento puntual y el abandono al ostracismo que no deja huella, esta es nuestra historia en la cultura, aún más en el cómic español reforzado en su condición de territorio de la masculinidad.

El vaivén histórico no es ninguna novedad para nosotras, pero ahora cada vez más sabias - necesitamos saberlo apurar dialogando con nuestra genealogía en construcción, porque éste es un resultado sembrado y mantenido con la constancia transgresora de las pioneras: las mujeres desde siempre han actuado en todos los ámbitos de la comunicación. Los cambios culturales tan solo se vuelven posibles si se alimentan desde la resistencia con visión de futuro y en continua tozudez esperanzada porque, aunque son lentos, también son imparables. Finalmente se empiezan a romper las compuertas del poder que nos ha seguido modelando en el binarismo asimétrico al ser traspasado, desde los viejos patriarcas a sus ilustrados herederos, en la fraternal complicidad con la que la modernidad nos reconstruye en sus discursos. Y es que, los diques que empiezan a mostrar sus impotentes grietas se encuentran en la base de las tecnologías del género de las que nos habla Teresa De Lauretis, que establecen las instituciones, los medios culturales y de comunicación, etc. A través de ellas se nos construye en la arcana asimetría de género que la modernidad nunca desmontó, observemos que tan solo ha considerado la necesidad de disfrazarla para mantener un control asegurado por su naturalización.

MARINA BETTAGLIO: El cómic como medio de comunicación de masas ejerció durante el franquismo una notable influencia en la pedagogía de género. Pensamos en las publicaciones destinadas a la infancia como Mis Chicas o en las colecciones destinadas a un público femenino, desde Azucena a los Cuentos de hadas y, más adelante, Mary "noticias" y muchas otras. Todas 
ellas, con sus diferencias, constituyeron un potente vehículo de difusión de estereotipos de género que marcaban lo que significaba pertenecer al género femenino. ¿Cómo han cambiado los cómics y cómo se han gestado dichas transformaciones, sobre todo en cuanto a la construcción de un imaginario de género?

MARIKA VILA: El cómic es un lenguaje cultural, uno más entre los muchos medios del arte popular con los que se expresa cada sociedad y a través de los cuales se puede tomar la temperatura al estado de sus valores, a su evolución cívica y al nivel de su progresismo. Sus características lo convierten en instrumento social creador de modelos, en espejo de los equilibrios y las fluctuaciones del poder, pero en ningún caso asegura que su discurso sea un fiel reflejo de las voces reales, antes bien es un modelador de voces. Es por eso que durante la dictadura ha sentado sus bases en el reflejo de la ideología dominante separando niños y niñas en productos diferentes que los condicionaron de forma asimétrica: las dejó a ellas encerradas en el estrecho ámbito doméstico preparando un corto viaje hasta la boda, mientras abría a los chicos las puertas del resto del mundo para su formación protagonista y heroica en los valores patrios de fraternidad guerrera. Son las claves masculinas del romanticismo aventurero las que sirvieron para la evasión infantil del mundo triste y gris de la postguerra: ¡Acción y aventura para conquistar el universo hasta el infinito y más allá de las estrellas...! Las chicas eran el botín de fondo. La nostalgia, que forma parte de un lazo sentimental tan positivo con la infancia, fundamentó la relación emocional de los chicos con el medio, pero no existió esta identificación emocionante para las chicas, sino un adiestramiento sicológico y social en el rol subalterno y el consumo.

Es interesante observar esta diferencia de enfoque ya que, en gran medida, en ella se forma la cantera que ha engrosado las filas de fidelidad en los lectores y ha formado parte de las fantasías de los creadores, editores o críticos de este ámbito, en el que se fue perpetuando la perspectiva homologada en el diálogo masculino. Así pues, observamos que lo que el medio expresa no es la voz completa de la sociedad sino la asimetría en la distribución de los espacios que construye el género: el desequilibrio de poderes sobre los lenguajes y las herramientas de comunicación que construyen la realidad simbólica y que así se encarnan en nosotros y se reproducen en nuestra vida cotidiana.

MARINA BETTAGLIO: ¿Cómo afectó el avance tecnológico al desarrollo del cómic por parte de las artistas gráficas españolas? 
MARIKA VILA: El cómic ha sido un perfecto instrumento al servicio de estas tecnologías, dada su capacidad de síntesis a la hora de generar modelos y gracias a la gran eficacia del impacto emocional en sus imágenes, pero la importancia de la cuestión que vamos a tratar estriba en la drástica variación de las formas de acción y recepción comunicativa establecida entre el cómic y la interlocución femenina con su discurso mediático a partir de las estrategias de resistencia de las autoras y la voluntad de presencia de las lectoras, hasta ahora siempre ignoradas. La desobediencia activa ha sido la pauta con la que las creadoras españolas han ido modificando las murallas defensivas del perfil genérico del mainstream, 4 cuyo monopolio en el contexto español giró en torno a la actividad de las editoriales comerciales como Cliper, Toray, Hispano Americana de Ediciones B de Barcelona. ${ }^{5}$

MARINA BETTAGLIO: Como indicas en tu ensayo "Las autoras españolas en el boom del cómic adulto. La mordaza patriarcal y el silencio roto", la situación de invisibilidad y marginación de las mujeres que "la dictadura mantuvo ... ausentes del discurso oficial ... fue transcendida por algunas autoras tras los arduos esfuerzos reivindicativos que abrieron las puertas a la transformación del cómic en los años 70, pero su incidencia ha permanecido ignorada durante un largo periodo de oscuridad" (204).

MARIKA VILA: Las autoras rebeldes se encuentran en todas las etapas de la historia del cómic y se caracterizan por romper con las normas del discurso e invadir los espacios secuestrados por el género. Sus estrategias coinciden en modificar los imaginarios para rescatar la iconografía de la voz masculina que ha venido ocupando sus cuerpos y problematizar su representación para dejar fluir las nuevas formas de subjetividad activa: autoras y lectoras salen de las sombras y demandan agencia para construir sus modelos.

Ana Miralles, Teresa Valero y Montse Martín, o Emma Ríos y Natacha Bustos, por ejemplo, adaptan hoy su creatividad a la comercialidad del encargo en el proyecto del mainstream americano y europeo, pero dejan su rastro en la interpretación iconográfica que crea un lenguaje propio desde el que nos hablan sus cuerpos dibujados, una vez liberados ("desokupados") del artefacto usurpador, al mismo tiempo que buscan otras vías más libres de expresión en las líneas minoritarias. Las creadoras con mensaje propio nos llegan con el aire fresco del cómic independiente. Lo han creado en solitario, o bien formando parte de equipos comprometidos con el cambio de modelos.

En la última década encontramos en este ámbito nuevas voces ya consolidadas o en proceso de hacerlo, como las de Olga Carmona, Cristina Durán, Sonia Pulido, Susana Martín, Isabel Franc, María Llovet, Mamen 
Moreu, Raquel Córcoles, Luci Gutiérrez, Clara Tànit Arqué, Lola Lorente, Ana Galváñ, entre tantas nuevas firmas femeninas que aportan sus experiencias o se arriesgan directamente por el camino experimental iniciado por sus rebeldes antecesoras.

Núria Pompeia en $1964,{ }^{6}$ Montse Clavé, Marika Vila y Mariel Soria a final de los 70 junto con Laura Pérez Vernetti, Ana Juan y María Colino, que llegaron algo después, iniciaron un planteamiento discursivo con el experimento a finales del siglo XX que continúa hasta hoy y es con quien dialogan las nuevas voces de Luci Gutiérrez, Flavita Banana, Conxita Herrero y muchas otras; así como Emma Ríos, Antonia Santolaya, Raquel Lagartos o Ana Penyas, por citar algunos de los ejemplos más recientes con las que he trabajado este año en la Semana Negra de Gijón.7 La positividad de los cambios logrados nos permite ver el triunfo en la actitud de las mujeres del siglo XXI. Ellas llegan fuertes y dispuestas al empoderamiento para unirse a sus madres y abuelas, aun activas, al reclamar el fruto de una larga trayectoria de pertinaz resistencia tras el silencio institucional y mediático: tienen voz y la usan, son receptoras y exigen atención.

MARINA BETTAGLIO: ¿Cómo se manifiestan las voces femeninas en el contexto actual del cómic español?

MARIKA VILA: El mismo efecto desconstructivo del discurso impulsado desde las voces femeninas empieza a vislumbrarse en el ámbito del cómic español en el que se hacen hoy visibles los signos del fenómeno, y esta es una gran novedad, ya que su territorio ha venido manifestándose tradicionalmente como un reducto pertinaz del discurso masculino, sordo a las voces que contradicen sus tópicos binarios y androcéntricos, y más resistente que otros a los cambios. Sin embargo, en este momento eclosionan con fuerza en sus escaparates institucionales los nombres femeninos que, a pesar de seguir en flagrante minoría, en 2018 reciben súbitamente la mitad de las nominaciones y los premios, dando lugar a que algunas voces del sector magnifiquen el acontecimiento del avance femenino, mientras otras cuestionan la inclusión de la perspectiva de género en los jurados de especialistas, frivolizando la validez de sus criterios. El cómic español tardó 40 años en dar su Gran Premio a las primeras firmas femeninas (Ana Miralles, 2009, Pura Campos, 2010), siendo la espectacular continuidad de la ausencia de mujeres en las nominaciones la causa de un manifiesto de denuncia que leyó la autora nominada por el cómic Gran bola de helado en el Salón Internacional del Cómic de Barcelona de 2017. La autora, Conxita Herrero, leyó dicho manifiesto en primera persona desde la indignación 
sentida al encontrar tan solo tres mujeres entre los treinta nominados a los premios de ese año.

Sin embargo, las consecuencias de la suma de activismos feministas parecen haber aportado una repentina eficiencia de resultados: en la siguiente edición del Salón, la mitad de las nominadas a los premios de 2018 han sido mujeres y finalmente los premios más importantes han recaído merecidísimamente en dos espléndidas autoras: la veterana Laura Pérez Vernetti recibió el premio por su larga trayectoria, y la novel Ana Penyas fue premiada como Autora Revelación. Cabe destacar que el Salón de Barcelona por primera vez ha tenido como directora a una mujer, Meritxell Puig. Es posible que esta circunstancia haya impulsado favorablemente la novedosa abundancia de nombres femeninos en la participación de este año. Se añade a las buenas noticias que se inicie también una feminización real (con poder de decisión) de las instituciones de este medio. El Salón también acogió al Colectivo de Autoras de Cómic (AC) que ha concedido este año su premio a una pionera, en esta ocasión el homenaje fue para la autora de la Transición, Montse Clavé $\left(95^{-96}\right)$ y finalmente, por votación popular, me ha sido concedido el 25 Premio Ivà (en honor del gran dibujante que en la Transición representó la transgresión y el cambio desde el humor de El Papus), premio que recibiré en la ceremonia que se organiza en el Castell de Cornellà el nueve de noviembre de 2018 .

En el conjunto de sus contenidos, este Salón ha prestado más atención a la mirada feminista y se ha podido observar un aumento en las charlas, seminarios y entrevistas específicamente dedicadas a las autoras pero también se ha notado una mayor presencia femenina en la composición mixta de mesas redondas y jurados. El Salón también ha contado con mi participación a través de un seminario impartido con gran éxito de público joven de ambos sexos (lo cual es una gran noticia) y con mi presencia como pionera en las mesas que homenajeaban a los autores del Boom del cómic (1977). En ambas ocasiones el Salón ha recibido mi felicitación por sus cambios repentinos hacia la buena dirección, pero también mi advertencia de que el camino es largo, ya que la paridad aún queda muy lejos.

Como colofón, y antes de acabar un año tan fecundo, el Premio Nacional de Cómic 2018 ha recaído en la fantástica obra del premio revelación de Barcelona Estamos todas bien. En dicha obra, la joven autora Ana Penyas rescata la historia olvidada y nos habla de sus abuelas a través de un grafismo innovador que trabaja el lenguaje de los cuerpos para expresar la voz de la generación silenciada en la postguerra y su diversidad oculta que aparece narrada entre líneas por sus trazos vitales.

El panorama general parece indicar que hay razones para el optimismo pero, si damos por hecha la supuesta feminización del medio de la que 
algunas editoras hablan con esperanza, y antes de caer en las trampas a las que una simplificación superficial podría llevarnos de la mano de un temprano halago, estaría bien contextualizar la historia de la que procede la perniciosa asimetría que nos ha venido sepultando en la ausencia oficial.

No estará de más resaltar la condición de excepcionalidad con la que se ha destacado normalmente a cualquier mujer visible o premiada, con ello se ha construido uno de los hándicaps femeninos por excelencia, al conseguir que la autoría femenina -contemplada como rareza - sea eternamente una recién llegada al medio y carezca de anclajes históricos con los que dialogar, apoyarse o contrastar para tejer nuevos discursos. Esta circunstancia facilita que, tras la alharaca a la excepción, si no se establecen los lazos en un diálogo que construya su arraigo, su rastro desaparezca sin solución de continuidad.

MARINA BETTAGLIO: Si echamos la vista atrás, comprobamos la necesidad de rescatar la trayectoria femenina en el cómic español. ¿En qué medida las autoras han participado en la compleja historia de la narrativa gráfica antes y después de la dictadura?

MARIKA VILA: Los parámetros de este medio han funcionado así desde su origen republicano, ya desde su inicio, a principios del siglo $\mathrm{XX}$, en las revistas satíricas catalanas (Patufet, Mainada, La Nuri) o en las de pedagogía anarquista (Porvenir). En dichas publicaciones, yacen olvidadas autoras modernistas como Lola Anglada, Josefina Tanganelli (Abel) o Rosa Galcerán, entre otras que desaparecen a la sombra de los autores del momento, diseminadas por las revistas de Madrid o Valencia en la misma época, (como Pitti Bartolozzi a la sombra de su padre, Salvador Bartolozzi, por ejemplo) las cuales probaron con gran dignidad su valía al lado de los grandes nombres masculinos que las ocultan y nos impiden recordar su calidad.

La discriminación se acentúa en la segregación obligatoria a partir de I939, cuando las autoras atraviesan la negra dictadura con su creatividad agrupada y limitada al cuento infantil, los tebeos para niñas y el cómic femenino - ya que fueron considerados como su sitio natural - era el lugar donde la ideología fascista y patriarcal impuso sus preceptos para la formación en los roles de género hasta la boda y la clausura en el hogar. El silencio es la condición femenina por excelencia, o eso quiere inculcarnos el sistema en todas las épocas... "Me gustas cuando callas porque estás como ausente...", pero también, desde la contestación, tras el supuesto halago, el poeta progresista nos demanda esta condición para ser aceptadas como musas siempre mudas. 
La historia del cómic - también en el ámbito internacional, pero aún más exageradamente en el español a causa de la dictadura - nos permite constatar esa continuidad en la masculinidad de un discurso dominante que ha contribuido de forma importante a la construcción de las etiquetas clasistas y discriminadoras en sus modelos, al tiempo que ha venido reduciendo sistemáticamente la expresión de las mujeres al estrechar el acceso de las profesionales y al encerrar en el encasillamiento doctrinal a las lectoras.

Del cómic llamado femenino podemos rescatar a las grandes creadoras de estilo como Pili Blasco (Mis Chicas, I94I-1950), María Pascual ${ }^{8}$ o Carmen Barbará (Mary "noticias", 1962) junto a la anteriormente mencionada Rosa Galcerán, creadora de la colección Azucena (1946-1971), pero es muy corriente encontrar en gran número las firmas simplificadas $\mathrm{y}$ minusvaloradas bajo un diminutivo y sin apellido (Montse, Juli, Maribel, Fina, etc.), hecho que deja rastro de su presencia pero conduce a un anonimato difícil de subsanar por parte de la investigación.

En la etapa que recorre la postguerra hasta el final del franquismo y atraviesa la Transición española a la democracia (1939-1977), podemos rescatar más de Ioo nombres autorales en las publicaciones femeninas e infantiles con gran éxito de público, entre los que destacan con luz propia las de Pura Campos (Esther y su mundo, I971-1988), Trini Tinturé (Lily, 198I), Gemma Sales (Carol, 1965), Montse Clavé (1963), Ángeles Felices (19802000) Marika Vila (1974) o Mariel Soria (Cavall Fort, 1974) y muchas otras.9

Pero el producto romántico, pese al intento de modernización del tópico en un paradigma de libertad "tutelada" como el que modelaron las protagonistas (Lilian, azafata del aire, Mary "noticias" o Esther) que emergen a partir de la segunda mitad de los años sesenta, no deja de responder a la imposición del discurso patriarcal y no refleja suficientemente la diversidad de las lectoras, que lo abandonarán a finales del siglo XX al no hallar una representación adecuada a su realidad. Como veremos al analizar la creación del cómic de autor, Montse Clavé, Mariel Soria y yo misma, Marika Vila, seremos las primeras autoras en romper el techo de cristal del espacio femenino y unirnos al humor combativo y ácido de Núria Pompeia (Maternasis, 1967) para el asalto feminista al discurso androcéntrico desde la denuncia y la crítica. Se inicia entonces una resistencia activista dentro de los nuevos soportes del cómic adulto que se reestructura en la Transición con el proyecto de cambio de imaginario, paradigma y lenguaje.

MARINA BETTAGLIO: Si me permites la interrupción, al leer las aventuras de Mary "noticias" o de Esther, se podría imaginar que la vida de las chicas españolas en los años 60 y 70 era mucho más glamorosa, libre e 
inconformista de lo que realmente era: ¿podrías analizar este aspecto de los cómics aparentemente destinados al público femenino?

MARIKA VILA: Según el investigador Juan Antonio Ramírez (1975), Azucena (cuentos morales de hadas) es la colección que ejerció la influencia pedagógica más fuerte en las mujeres nacidas entre 1940 y 1960. Esta es una afirmación que deberíamos matizar, ya que, si bien Azucena tenía un fuerte componente pedagógico tradicional - basado en los cuentos fantásticos que preconizaban las virtudes femeninas centradas en la abnegación, la bondad, el sacrificio y la obediencia - no fue de las más nocivas, ya que mantenía una diferencia substancial con las otras colecciones contemporáneas y supuestamente más modernas. Estas eran dirigidas a una nueva clase en un falso reflejo de ascensor social, extendiendo el glamour del cine americano en su estética de falsa liberación. Azucena se dirigía a sectores más populares potenciando, a través de los cuentos tradicionales, las virtudes morales de las niñas, mientras las nuevas colecciones surgidas del Pop de los años 50 y 60 se dirigían a una nueva clase media que se quería identificar con el estilo de vida moderno y lujoso en conexión con la imagen que daba el modelo americano, pero absolutamente lejano de la realidad del país. La verdad fue que los electrodomésticos tardaron en llegar y los deportes eran un lujo para las niñas que veían a sus modelos montar a caballo o esquiar y ser recogidas o conducir coches aerodinámicos.

Además, en los años 6o, las mujeres aún tenían que pedir autorización a padres o a maridos para sacar el pasaporte, tener cuenta corriente, alquilar un piso o tener carnet de conducir... Implantar este ilusorio modelo constructor del consumo sin eliminar ni un ápice de los roles femeninos clásicos como deberes de formación, ni ampliar una página después de la boda como horizonte máximo de las historias femeninas, es lo que progresivamente fueron haciendo las revistas como Florita, y Mis Chicas o las posteriores colecciones románticas como Serenata, Rosas blancas, Sissi o Claro de luna, del mismo modo que el protagonismo estrecho y frívolamente afincado en los rasgos de inconsistencia, irreflexión y volatilidad que hacían a lo femenino víctima necesitada de rescate final son los que sostenían la apariencia de modernidad en las nuevas heroínas al servicio del discurso patriarcal. Construir la imagen modélica de una burguesía emergente fue el objetivo en el que se estructuraban las nuevas funciones que recaían sobre la representación de la identidad femenina: astucia para cazar marido y convertirse en su controladora (según el ideario falangista de José Antonio Primo de Rivera, no todo sería desechable en las veleidades feministas, quizás estaría bien convertir a la mujer en la cincha que sujeta el globo volátil de la inmadura imaginación masculina y, cómo no, en impulsora del 
consumo). En todas ellas encontramos añadida la fuerte ideología de clase y un modelo claro del patrón femenino que la ideología del franquismo asociaba a la imagen deseable del desarrollo español.

MARINA BETTAGLIO: Sin duda, como subrayas en numerosas publicaciones, la época de la Transición fue fundamental en cuanto al desarrollo de una poética visual en la cual el cuerpo femenino sexuado constituyó un referente de primer orden. ¿Cómo se configuran los cambios en la representación de la mujer durante este período? Has hablado de "una respuesta femenina a la construcción del artefacto-mujer": ¿podrías explicar este concepto tan fundamental?

MARIKA VILA: El cuerpo de las mujeres, es decir su representación icónica, ha sido usurpado por el "artefacto-mujer" recreado a la medida de la mirada androcéntrica de forma universal y usado como anzuelo desde las diversas perspectivas masculinas para atraer lectores. Tanto el cómic comercial como el independiente o el underground lo han usado como excusa para modelar al modelo que nutre la narración histórica de lo masculino y que sostiene su protagonismo. La popularidad de esta influencia ha sido crucial para sostener determinadas actitudes reaccionarias normalizadas, especialmente en el imaginario global alimentado por el poder de los medios de comunicación de forma masiva.

El "artefacto-mujer" además de modelar la feminidad del patriarcado, evoluciona con la eclosión de la cultura pop y la expresión de los grandes movimientos contraculturales, para transformarse en ícono y bandera de la transgresión desde los años 6o. Mientras tanto, las voces de las autoras quedaban ocultas en las sombras del medio y las lectoras eran ignoradas, y con ello expulsadas de la participación en el discurso común. De hecho, abandonaron el cómic por las revistas rosas o fotonovelas las que fueron obedientes al mandato del sistema, o bien, si necesitaban su dosis intelectual para alimentar su fantasía aventurera, debían dirigirse hacia la literatura para encontrar más posibilidades de identificación, tan solo las más fieles apostaron por el travestismo - necesario para las niñas en el cómic - que permitía seguir las aventuras masculinas desde el papel activo aunque, en realidad, también eran rechazadas por las comunidades del propio ámbito en sí (lectores, librerías, convenciones y salones durante mucho tiempo han sido feudos masculinos en los que las chicas no hallaban lugar propio).

Esta confluencia de circunstancias que acapara y segrega el territorio mediático ha construido un diálogo unilateral favoreciendo su naturalización en la ausencia de la voz de las autoras silenciada tras un 
cuerpo secuestrado por la voz ajena. El paradigma del artefacto "mujer" que supuestamente nos representa y domina la iconografía del medio en los años 70 tanto en Italia, país de referencia en cuanto al cómic erótico de autor, como en España, sería el personaje de Valentina. Guido Crepax, el intelectual y gran renovador del lenguaje del cómic europeo, la presenta a sus lectores como portavoz de una revolución icónica. Renueva el estereotipo con su Valentina (1965-2012) ro y la transforma en musa de la transgresión que libera la represión masculina.

Aunque la crítica ha insistido en considerarla modelo de mujer liberada, Crepax siempre nos ha informado de que el artefacto responde a sus fantasmas y a la construcción de su mirada erótica. Si analizamos su obra, encontraremos infinidad de claves y códigos a descifrar en los que Crepax se confiesa plenamente y nos muestra al interlocutor culto al que se dirige en su relación intelectual con el pensamiento filosófico transgresor de la época para plasmar al nuevo sujeto de la postmodernidad: el sujeto descentrado que abandona el protagonismo central para controlar el mundo desde los márgenes del sistema (Neutrón) y su marioneta (Valentina), que es a quien sitúa en el centro del escenario en actitud de exposición pasiva, y sujeta al poder de su control mental para ofrecerla al lector con quien dialoga.II

MARINA BETTAGLIO: ¿Es la corporalidad del medio un aspecto esencial del cómic tanto de autoría masculina como femenina? ¿Qué significa que haya un "cuerpo ocupado" de la mujer?

MARIKA VILA: Cuando hablamos de iconografía, hay que hablar del cuerpo como lugar de conflicto. Las representaciones que construimos nos construyen a su vez al ser aceptadas y nos modelan al encarnarse en nosotros performativamente. El cuerpo como textualidad está cargado de signos que la cultura le inscribe y con los que lo transforma en etiquetas de género, de identidad, de clase, etc., que nos aprisionan. En este campo de batalla, el empoderamiento de las voces femeninas ha encontrado una primera y principal dificultad al problematizar su propia representación: las autoras se han enfrentado a un cuerpo ya usurpado, un icono vacío cargado y simbólicamente resignificado por la voz de la creación masculina a la medida de su necesidad, de forma tan viciada que imposibilita su interacción natural.

El tratamiento del cuerpo ha sido uno de los elementos de contraste en el trabajo de las mujeres invisibles que desde los orígenes podemos rastrear y rescatar del olvido en la historia del medio, sus estrategias varían, pero coinciden siempre dentro del contraste y la ruptura con el modelo 
imperante. La clave se encuentra en la exigencia de voz y en la propiedad de la mirada para tomar conciencia y desnudar al artefacto de su disfraz, desmontarlo y vaciar sus falsos mensajes así descodificados.

El cuerpo y la autorrepresentación son el eje sobre el que mayoritariamente giran las obras de las pioneras, ambos conceptos conformando el punto en común de las estrategias discursivas en unos trabajos que nos muestran la pluralidad y amplitud vanguardista de sus miradas. Después de milenios de invisibilidad en los que han sido representadas desde la ocupación unívoca - alterada en la falsa homogeneidad de su espacio corporal - las autoras sienten la necesidad urgente de reformular la diferencia junto con la diversidad de las imágenes que encarcelan y codifican una representación dentro de la cual se sienten violadas. El arma que surge naturalmente de su pluma contra la violencia icónica será la autorrepresentación.

Pompeia nos dibuja con el filo crítico de su mirada y nos muestra el camino en el minimalismo aparentemente ingenuo. Mi mano rompe las normas desde el expresionismo, elimina las redondeces femeninas y los límites concretos del discurso clásico para volar sobre la pluma y defender el espacio ganado en el experimento, su objetivo es desconstruir el "artefacto-mujer" y descodificar el cuerpo ocupado por los fantasmas del erotismo masculino. Luci Gutiérrez (2009), autora del nuevo milenio, simplemente expone sus normas, decide crear su propia sexualidad y su representación en ella. No reflexiona, no rompe, posee el poder naturalmente y sin complejos se autodefine; crea un espacio icónico y lo disfruta, limpio de códigos ajenos. Vemos cómo se produce de forma espontánea un diálogo intergeneracional entre los iconos de las autoras que une el discurso genealógico y le confiere coherencia.

Los trazos feministas en las autoras de la Transición española nos muestran cómo la pretensión de desocupar el cuerpo es una necesidad expresiva que se manifiesta en las diversas estrategias de supervivencia o ruptura empleadas. Sus grafías construyen espontáneamente un mensaje común, sin necesidad de consenso y éste pasa por liberar la propia representación del tópico y el estereotipo que había usurpado su voz.

Clavé recorre las sensaciones de la piel buscando simetrías en el autoerotismo poético de Mari Chordà. Marika da voz y acción reivindicativa al cuerpo de las princesas y las doncellas, o rastrea en la cuatricromía de la piel a la desconocida que esconde nuestra imagen construida tras la dependencia de la mirada ajena. Mariel Soria activa a las bellas femmes fatales dando vida a su roja cabellera que captura al violador, violado por su propia pistola. Con todas ellas comprobamos que cuestionar los modelos es des-ocupar el cuerpo. 
Podremos seguir este rastro en los años posteriores, buceando en los trabajos de Ana Miralles, Ana Juan, María Colino, Laura Pérez Vernetti, Marta Guerrero o Marta Cano y entrar en el nuevo milenio con Emma Ríos, Raquel Alzate, Sonia Pulido, Miriam Cameros, Clara Tanit Arqué, Luci Gutiérrez, Lola Lorente, Sandra Uve, Carla Berrocal, Cristina Duran, Isabel Franc, Susana Martín, entre tantas otras (la cita no es exhaustiva, sino que pretende mostrar la aceleración en la incorporación actual de firmas y sus títulos localizables en la red) que nos aguardan en las librerías o de forma virtual en sus blogs y en las tiendas online. Desde el análisis de sus miradas sobre los cuerpos y sus expresiones podremos observar las diferentes relaciones que establecen con la autorrepresentación cuestionando el género, presentando otros modelos, otras sexualidades, otras culturas y otros cuerpos.

MARINA BETTAGLIO: ¿Cuál es la influencia de Crepax en el cómic español de la Transición?

MARIKA VILA: Hay que tener en cuenta la influencia que Crepax marca en el concepto del nuevo cómic de autor y su imaginario en el ámbito español de la Transición democrática - especialmente en su concepción del nuevo estereotipo, supuestamente transgresor y libre. Es con este modelo, con el "artefacto-mujer" de la nueva transgresión liberadora a quien usurpa la representación Valentina (y tantas otras copias de las que es paradigma), con quien han de enfrentarse desde su hándicap de silencio las primeras rebeldías femeninas y comprender que, a pesar de tal exclusión de la acción, algunas mujeres, entre las que cabe destacar como pioneras comprometidas a Núria Pompeia, Montse Clavé, Marika Vila, Mariel Soria y, más tarde y desde distintas posturas Ana Miralles, Laura y María Colino, han continuado enfrentándose al modelo, resistiendo, creando y ganando espacios de representación, para dejar su mensaje, desvinculándose de la representación corporal que construye la mirada masculina. Por esta causa, es interesante recuperar lo no visto.

En cualquier espacio que busquemos con suficiente interés encontraremos las pequeñas cuñas que han dejado las mujeres en la construcción del cómic. No solo las creadoras han sido invisibles, también el conjunto de mujeres que han formado parte de los equipos de realización, ya sea las dibujantes, las coloristas y las guionistas en sus trabajos de encargo, o las coordinadoras del trabajo editorial (nunca dueñas de las decisiones finales, normalmente situadas en manos masculinas) o las técnicas editoriales, las redactoras, grafistas, rotulistas, etc. Finalmente han llegado las analistas, las investigadoras y las teóricas al rescate y hoy el 
discurso del cómic empieza a aparecer bajo perspectivas más plurales. Ese trabajo oculto y de resultados lentos merece ser recordado para ver sus frutos en el giro que empiezan a tomar sus instituciones - tanto la expectativa académica, como las líneas editoriales o las estructuras que le dan cobertura oficial - gracias a una nueva actitud de las lectoras antes expulsadas y recuperadas hoy fundamentalmente por el manga y por la nueva y reforzada aparición de las autoras asociadas. Ahora han vuelto pisando fuerte y con una exigencia que llega para quedarse. ${ }^{12}$

MARINA BETTAGLIO: Creo entender que, como indicas en otras publicaciones, durante la Transición el lenguaje del cómic sirvió para impulsar importantes cambios sociales que transcienden el ámbito de la narrativa gráfica.

MARIKA VILA: El cómic es mucho más que su ámbito mediático, es un lenguaje sintético y pedagógico que sobrepasa su medio específico y ha sido ampliamente usado por el activismo feminista en sus panfletos y documentos de difusión para llegar a las mujeres en su revolución, de la misma manera en que lo han usado los demás movimientos sociales como herramienta pedagógica.13 El medio siempre podrá contemplar este aporte como riqueza, aunque durante mucho tiempo no lo haya valorado.

Es por ello que la obra de las pioneras se compone de las dos bandas del compromiso y se multiplica desde los panfletos hacia la lucha social - al reflejar e impulsar la necesidad del momento político - a la denuncia crítica y el experimento gráfico dirigidas a impulsar la renovación plástica del lenguaje y el medio en las publicaciones dirigidas a la construcción del cómic adulto. Durante años el cómic innovador de las autoras ha quedado oculto entre las curvas de los artefactos femeninos que tanto espacio han ocupado en el discurso. Su trabajo ha tenido que buscar su lugar fuera de un territorio manifiestamente hostil como ha sido el cómic mainstream o incluso ha sufrido el rechazo discriminador en el marco contracultural, pero eso no excluye la importancia que ha tenido el cambio que se produce en el lenguaje a partir de las revoluciones feministas de los años setenta, gracias tanto a su persistencia como a su estrategia resistente. Desde las cargas de profundidad en la línea ingenua y aparentemente inofensiva de Pompeia o de Clavé, hasta la acritud del expresionismo rompedor en mi pluma, en la de Laura o en la de Mariel, la ironía y el sarcasmo han sido las armas que han abierto brechas en el muro del discurso monolítico dominado por los estereotipos. La constancia en la resistencia ha sido su valor y se ha producido simultáneamente en los diversos escenarios internacionales de forma espontánea y sin conexión previa entre las autoras, como podemos 
ver en la primera antología aparecida en España (Totem. Especial Mujeres 1977). La simiente crece ahora con fuerza y emerge exuberante en el empoderamiento de las nuevas creadoras, desborda los resquicios creados en el discurso sistémico para variarlo.

Las autoras de los años setenta (Pompeia, Clavé, Soria, Vila) rompieron los límites de género e irrumpieron en el espacio de la masculinidad derrumbando estereotipos y sembrando las grietas que abrirían el discurso a nuevas perspectivas. Su paso no solo ha significado un eslabón importante al que pueden recurrir como referente las nuevas voces, sino que también llegaron a abrir las mentes a nuevas sensibilidades masculinas imbuyendo las bases de un nuevo imaginario desde el activismo en el inicio de los cambios discursivos. Este giro se ha reflejado principalmente en el cómic independiente bajo el formato de novela gráfica, en el que ha evolucionado el cómic de autor actual, pero finalmente han acabado modificando aunque sea superficialmente - también al cómic clásico y sus tópicos. La influencia llega hasta el punto de inquietar tanto al núcleo duro del machismo que el movimiento conservador denominado Comicsgate se está organizando para frenar las modificaciones que hoy exigen las nuevas miradas -fundamentalmente las lectoras, pero también la representación de la diversidad - en el cambio de modelos. Marvel y DC consideraron desde el punto de vista comercial la oportunidad de ir introduciendo pequeños y superficiales giros en esta dirección y eso parece haber excitado algunos demonios en la androcéntrica mirada machista de los fans que es aplaudida y alimentada por el neoconservadurismo occidental en su batalla acérrima contra la diversidad. ${ }^{\mathrm{I}}$

En todas partes, las instituciones del cómic han sido también fruto y parte de la misma asimetría: editores, críticos y jurados han surgido del mismo diálogo y lo han alimentado construyendo un mercado desde los mismos presupuestos como territorio masculino durante la mayor parte de su historia. Una buena muestra de ello la encontramos al comprobar que la aguda masculinización del cómic en España repite el patrón de sus hermanos mayores en el cómic internacional. Lo comprobamos en la generalización histórica de una minoritaria participación femenina en el cómic mainstream, pero también en la tardía recuperación de los trabajos de las pioneras del movimiento underground americano, por ejemplo, desconocidas hasta hace pocos años. ${ }^{15}$ Curiosamente, a pesar de la distancia y la falta de contacto entre unas y otras creadoras, podemos encontrar las mismas coincidencias estratégicas en la transgresión de los tópicos sobre la femineidad y el ataque al cuerpo del "artefacto-mujer" o a las convenciones desde las que se nos construye en el género. ${ }^{16}$ 
En el humor español, y en un contexto tan reincidentemente masculino que se revaloriza como elemento liberador reafirmándose en el machismo que domina la sexualidad a finales de los años 6o, es donde se debe contextualizar el trabajo de Núria Pompeia, que surge abriendo camino al grito con el que, a continuación, las pioneras del cómic adulto romperán las costuras del espacio femenino. Un grito estratégico con el que han seguido haciendo trocha en la selva erótica del destape hasta la revisión de la pornografía desde la agencia del feminismo millennial, manteniendo presencia en el discurso y resistiendo firmes en la denuncia de la falta de referentes. Todas ellas formaron parte de los colectivos renovadores comprometidos políticamente con el cambio.

MARINA BETTAGLio: ¿Podrías profundizar en el compromiso político de la llamada Generación del Compromiso que se abrió paso a finales de los años 60 y en los 70 ?

MARIKA VILA: En el declive final de la dictadura y en pleno proceso de Transición democrática, la lucha de algunos profesionales recuperó el lenguaje del cómic - es decir, la herramienta a través de la cual se expresaba su trabajo fundamentalmente encasillado en un marco de normas y límites establecidos por la censura y la comercialidad - rescatándolo del lugar menor (en tanto que infantil) que ocupaba, para impulsar un cambio temático y crear un espacio donde poder recuperar la autoría responsable conectada con los cambios sociales.

Aupado por la revalorización estética que recibió desde el concepto de cultura popular de Warhol y del análisis semiótico con el que Umberto Eco lo señaló como objeto de estudio, en España el medio se situó en el centro del escenario a partir de las teorías sobre los medios de difusión masiva de Marshall MacLuhan como herramienta codificada de experimentación. Se recuperó para la autoría individual como un arma cargada simbólicamente de doble lenguaje, en el mismo momento que el país necesitaba y demandaba la libertad de expresión. En la España de la Transición a la democracia, el cómic comenzó a crecer, transcendiendo el mundo infantil y la frivolidad del consumo rápido, y se convirtió en un adulto interesante que atrajo la atención general.

Los autores implicados crearon las bases para la emergencia de un cómic adulto, que en un principio se asoció al compromiso con el activismo social y la lucha política, pero que evolucionó también hacia una revolución estética y formal que transformó el mundo de la historieta. Dentro del mismo ámbito segregado trabajaban también en 1975 las ilustradoras de cómic infantil y de romance que fueron las nuevas pioneras del boom. 
Montse Clavé, Marika Vila y Mariel Soria formaron parte del Colectivo Butifarra, del Colectivo de la Historieta y de las muchas revistas (Bang! Trocha, Troya, Butifarra, Rambla, Cul de Sac, Totem, El Papus, El Jueves, Gimlet, etc.) y activismos comprometidos política y socialmente con el momento (Club DHIN, Sindicato de dibujantes, Salón del Cómic de Barcelona, etc.) que conformaron la posteriormente llamada Generación del Compromiso, por estar basada su acción en esta premisa.

Como sus compañeros, Clavé, Vila y Soria se implicaron en la revolución de la que surgieron las nuevas maneras de entender el cómic, los nuevos soportes y la renovación de su lenguaje, pero lo que las convierte en autoras vanguardistas es la apuesta por romper los límites de la segregación para irrumpir en territorio masculino como alteridad, asumiendo la ruptura e impulsando los cambios en las temáticas y los estilos de la nueva historieta. $\mathrm{Su}$ objetivo fue apropiarse del mensaje y propiciar un nuevo lenguaje icónico, desde la exclusión hacia la inclusión de la diversidad en el diálogo común. Necesitaron reclamar su visibilidad al comprobar en la propia circunstancia que toda su colaboración en las luchas y trabajos para la renovación del medio y en pro de los derechos de autor sufría la doble discriminación de género. Eran ignoradas inconscientemente por sus compañeros, por el medio y por las mismas instituciones que ellas habían colaborado a fundar (sindicatos, Salón, revistas etc.).

Núria Pompeia, Montse Clavé, Marika Vila y más tarde Mariel Soria, siguieron siendo una minoría tan solo visible a fuerza de grito y voluntad reivindicativa, la diferencia fundamental con las autoras del cómic romántico asignado al género, del que ellas provienen (excepto Núria) es la asunción de responsabilidad sobre el mensaje, el esfuerzo por irrumpir en el ámbito masculino y por luchar codo a codo por su mejora y su consideración artística en pie de igualdad.

MARINA BETTAGLIO: Leyendo tu análisis de las obras de las dibujantes españolas, en particular de autoras transgresoras y reivindicativas como Núria Pompeia, Montse Clavé y tú misma, surgen algunas dudas. ¿Quiénes leían sus obras? ¿Cómo se valoraban sus obras en aquel entonces?

MARIKA VILA: Tanto Núria como Mariel o yo publicamos desde la Transición en todas las revistas que leían básicamente hombres y algunas mujeres acostumbradas a transvestir su identidad lectora, dada la falta de referentes protagonistas activos fuera del erotismo (y aun allí más pasivos que activos, digamos que expuestos). El feminismo, sin embargo, no se acercaba al cómic, ya que era un territorio prácticamente cerrado por la masculinidad (por un machismo espectacularmente dominante). Durante mucho tiempo 
no fue de su interés entrar en este espacio, aunque usaba ampliamente su lenguaje para hacer pedagogía (colaboramos todas con panfletos, carteles, publicaciones educativas en los barrios, etc.) Pero nuestra persistencia en el territorio masculino marcó a algunas lectoras (como Ana Miralles o Laura P. Vernetti, y ellas, a su vez, a las siguientes) para decidirse a seguir nuestros pasos y tomar el testigo. También ayudó a algunos compañeros a cambiar su mirada y a desnaturalizar lo obviamente impuesto: las construcciones de género y sus limitaciones para ambos sexos.

El activismo de las autoras comenzó a ganar espacios y a marcar límites denunciables desnudando tópicos y desmontando estereotipos. Por supuesto nuestro público fue minoritario (y aun hoy, pese al sorprendente aumento, sigue siendo una minoría en el ámbito) pero se abría un camino que se ha ido ampliando a base de resistencia y tenacidad.

Como todo trabajo de vanguardia el impacto es importante para el movimiento pero el recuerdo es efímero; hay que buscarlo en la raíz de los futuros frutos. Las autoras han sufrido especialmente esta circunstancia ya que el impacto mediático se ha asociado generalmente al "ser mujer" a la moda y a la "excepcionalidad", desarraigando su trabajo y transformándolas siempre en recién llegadas a un club antiquísimo cuyas normas no las contemplan. De todas formas, cada una en su diversidad ha sido respetada y apreciada por alguna minoría, todas hemos vivido de esta profesión, como la gran mayoría de autores, y las que han escogido la competición comercial, como es el caso de Miralles, Emma Ríos, o incluso Laura Pérez Vernetti en el ámbito experimental, a base de resistencia han conseguido un esforzado éxito internacional.

MARINA BETTAGLIO: ¿Cuál es el resultado de los esfuerzos de las pioneras del cómic español en las nuevas generaciones? ¿Cómo ves el futuro del cómic de autoría femenina en España?

MARIKA VILA: No ha sido hasta fecha muy reciente que el trabajo constante de resistencia y denuncia en el esfuerzo por crear un lenguaje nuevo de las pioneras ha encontrado eco en una nueva generación de autoras que recuperan la voz y afirman presencia (desde el espacio virtual de las blogueras a la autoedición o las publicaciones en papel), asociándose y creando la fuerza para ganar territorios y recuperar el discurso y el diálogo con las antecesoras. Así nacen diversos proyectos activistas para la construcción del diálogo intergeneracional que culminan en noviembre de 2016 con la exposición Presentes. Autoras de tebeo de ayer y de hoy, organizada por el colectivo de Autoras de Cómic (AC) y patrocinada por el 
Ministerio de Asuntos Exteriores y de cooperación (AECID) que mantiene una itinerancia internacional por las embajadas españolas.

El hecho asociativo ha marcado un antes y un después en el activismo y la búsqueda de visibilidad por parte de las autoras en España, sin embargo, en este momento parece ser que es el propio medio (editores, publicaciones, instituciones etc.) el que intenta cubrir cuotas y las necesita, al hacerse evidente su cojera temática y discursiva. El feminismo se ha hecho necesario como perspectiva social que amplía la mirada sistémica, los movimientos sociales han puesto su lucha en vanguardia de nuevo y la gran difusión de las redes juega actualmente a nuestro favor.

El cómic también se beneficiará con esta reincorporación a la visibilidad, siempre podrá esgrimir la importancia vanguardista de los trabajos de las autoras pioneras para restaurar su equilibrio en la interacción comunicativa. Desde el modernismo resistente de Lola Anglada y las republicanas, hasta el estilo naif cargado de explosivos de Pompeia o los juegos expresionistas y experimentales que iniciamos en la Transición, las autoras desbrozamos el camino hacia el discurso plural al impulsar la deconstrucción de estereotipos y la rotura de etiquetas en los nuevos relatos, desde ellos hoy las voces emergentes lo completan al aportar una mayor diversidad para la percepción social de la realidad que nos construye.

Como investigadora, llevo años recopilando información y rescatando el trabajo de las creadoras porque creo imprescindible complementar el discurso histórico del cómic con sus voces ausentes. Este ha sido un instrumento utilizado desde las ideologías por su capacidad sintética de transmitir mensajes camuflados bajo grandes palabras y dirigir embates a nuestra parte visceral para inyectarlos directamente en la emoción y, a través de ella (de)formarnos. Esta característica hace imprescindible reconfigurar el análisis de nuestros modelos sociales desde un medio tan popular como efectivo en la construcción pedagógica de las identidades de género, y usarlo ahora para la desconstrucción de los tópicos. ${ }^{17}$

Mi trabajo se ha centrado en crear la simbiosis punzante de palabras y líneas - de documentación y análisis también - para abrir grietas, descalzar cimientos y derrumbar el alto muro de los estereotipos por el que hoy ya se filtra claramente la voz de las mujeres... Al escucharlas, entenderemos la importancia de su ausencia en el discurso global.

\section{NOTAS}

I María del Carmen Vila Migueloa (Marika Vila) fue protagonista de la renovación del panorama del cómic a partir de los años 70. En años más 
recientes se ha dedicado al estudio académico de dicho género, analizando desde una perspectiva feminista el lenguaje del cómic y la construcción de la subjetividad femenina en dicho medio. El texto del artículo que ha realizado para nuestra revista (al que hemos dado formato de entrevista) ha sido modificado integrando en él los interrogantes que surgieron durante nuestro encuentro en su casa de Barcelona, el 29 de octubre de 2018 , algunas de las cuales emanan de la lectura de sus precedentes artículos. [Nota de Marina Bettaglio (MB).]

2 Nos referimos a todas aquellas voces que hablan como alteridad desde la diferencia y contradicen el discurso binario y androcéntrico, obviamente las de las mujeres desde la interseccionalidad de opresiones y también, pero no solo, a las de los grupos LGTB que protagonizan un grupo de presión emergente importante. [Nota de Marika Vila (MV).]

3 La multitudinaria huelga del 8 de marzo de 2018 , que ha llevado a la calle miles de mujeres españoles unidas en el rechazo de las desigualdades de género, ha demostrado la vigencia de un tipo de feminismo anclado en las vivencias de todas las mujeres, desde las más jóvenes hasta las más ancianas que han colgado sus delantales reclamando igualdad, corresponsabilidad, el fin de las violencias de género, de la brecha salarial, de las discriminaciones, del acoso sexual, del maltrato y de las estructuras patriarcales que mantienen a las mujeres en una situación de sujeción. [Nota de MB.]

4 En este caso, el mainstream, o corriente central y mayoritaria del mercado, se refiere a España, pero también al producto europeo y americano que se ha consumido en España y que no han diferido demasiado en el discurso homologado en la mirada androcéntrica y heteronormativa. Podemos así hablar de comic comercial o mainstream, comic independiente o underground. [Nota de MV.]

5 Sobre este aspecto se remite a La historia social del cómic de Terenci Moix que examina tanto el cómic internacional como el español. Sobre el rol de las artistas gráficas españolas en la época de la Transición, véase en particular el reciente volumen Derrumbando estereotipos. La subjetividad femenina en el cómic de Marika Vila, editado por la Semana Negra de Gijón. [Nota de MB.]

6 Para un análisis de la obra de Núria Pompeia, véanse el citado artículo "Las autoras españolas en el boom del cómic adulto. La mordaza patriarcal y el silencio roto" de Marika Vila y su tesis doctoral, El cos okupat. Iconografies del cos femení com a espai de la transgresió masculina en el còmic. [Nota de MB.]

7 En la celebración de la Semana Negra 20 I8 (Gijón) he comisariado, junto con Norman Fernández, una exposición alrededor de la idea de subjetividad femenina potenciando el diálogo entre generaciones. Sobre ella reflexiono en el libro Derrumbando estereotipos que la acompaña y que se publicó con motivo del evento. En el análisis de las obras expuestas se contextualiza su historia 
dentro del medio y se muestran la diversidad de expresiones sobre un mismo punto conflictivo: el cuerpo y su recuperación y resignificación. [Nota de MV.]

8 Ilustró las colecciones de Toray: Azucena, Rosas Blancas, Guendolina, etc. [Nota de MV.]

9 Al recordar el aporte de estas artistas gráficas, hay que señalar que algunas dieron vida a personajes seriados como en el caso de Pura Campos y Trini Tinturé, mientras que otras dibujaron tiras de diferentes temáticas que no están protagonizadas por un solo personaje. [Nota de MV.]

Io En los años 70, numerosos dibujantes internacionales, entre los que destaca el nombre de Guido Crepax, publicaron sus obras en España. Tanto en Italia como en España, el desinhibido personaje de Valentina fue muy controvertido. Según una parte de la crítica, se trata de "un personaggio trasgressivo, simbolo dell'emancipazione femminile e della rivoluzione sessuale" (Zanatta 72).

Frente a este tipo de interpretación, resulta necesario revisitar la construcción discursiva de una feminidad pseudoemancipada, vehiculada por la mirada y el deseo masculino. [Nota de MB.]

II Ambos no son más que el desdoblamiento de los alter egos de Crepax, sus partes masculina y femenina liberadas... (las del autor, en ningún caso las de Valentina). El artefacto mujer creado por la mirada progresista masculina ocupa el centro y modela (recupera y reestructura) el estereotipo, silenciando a las mujeres reales. Al aceptar la categoría de icono sexy o erótico, el artefacto retorna el control sobre las mujeres liberadas para devolverlas al rol de la exposición mítica que ocupa falsamente el protagonismo del sexo, no para ser sujeto sino para quedar sujeta(da) a la mirada masculina en su manipulación erótica. [Nota de MV.]

I2 El manga, o cómic japonés, a pesar del tradicional machismo en que fundamenta su cultura en la segregación, siempre ha tenido en cuenta a las mujeres como target diferente a quien transformar en consumidoras, es por esta razón que produce grandes cantidades de comics específicamente dirigidos a todas las franjas de edad femeninas y da espacio a muchas creadoras. Otra cosa será analizar sus contenidos, pero el gran éxito de su externalización ha afectado principalmente a un público huérfano de atención, como han sido las niñas españolas. [Nota de MV.]

I3 La importancia del empeño social de una dibujante comprometida como Núria Pompeia se puede comprobar en el libro de Mary Nash, Dones en transició. De la resistència política a la legitimitat feminista: les dones en la Barcelona de la Transició. [Nota de MB.]

I4 Y es que en el panorama histórico del cómic internacional también podemos observar el fenómeno asimétrico común con el que la mirada androcéntrica ha venido apropiándose del medio y su lenguaje. Esta es la causa universal que ha propiciado su transformación en territorio masculino por antonomasia, 
erigiendo al muchacho adolescente y/o al adulto inadaptado, en los receptores paradigmáticos del mensaje dirigido a sus represiones - obviamente las de un hombre - de forma que el imaginario se ha ido construyendo desde las voces masculinas (autores) en su relación con otros varones (lectores), situados en el otro lado de un diálogo en el que las mujeres tan solo han existido como iconos silentes de intercambio y en territorios corporales donde ubicar la lucha y negociación de sus fantasmas. [Nota de MV.]

I5 Trina Robbins, formada en los equipos Marvel, dibujante de Wonder Woman, y fundadora de la revista feminista Wimmen's Cómix, y sus compañeras pioneras en el cómic underground desde los años 80 del siglo XX (Mari Fleener, Roberta Gregory, Phobe Gloekner, Julie Doucet, etc.) forman parte de las voces que no llegaron en su día a los quioscos españoles ni recibieron en realidad la misma difusión y valor que los trabajos de sus colegas masculinos, aunque detrás de la revolución del lenguaje que supuso ese movimiento se encontraba su trabajo y sus denuncias feministas y de clase con tanto o más valor, pero que han debido esperar al nuevo siglo para ser apreciadas debidamente. [Nota de MV.]

I6 La misma carencia la podemos encontrar en el cómic europeo, en el que la minoría discriminada también se conjuntó por un tiempo breve en la revista ¡Ah! Nana (1970) donde Les Humanö̈des Associés reunió a las autoras francesas del nuevo cómic nacido en Europa a partir de los años 60 como lenguaje innovador. El cómic francés que asumió el liderazgo del cómic europeo, tradicionalmente ha tenido una industria interesada en las vanguardias y es el lugar donde históricamente encontramos reconocidas más firmas de mujer desde las pioneras Claire Bretécher, Nicole Claveloux o Chantal Montellier a las más actuales Catherine Meurisse, Julie March o Lou Lubies, entre muchas otras - pero su corpus sigue manteniendo una clara discriminación que lo enfrenta, también desde hace tiempo, a una fuerte crítica hacia las instituciones masculinas que construyen sus criterios. Sus autoras han sido pioneras en asociarse al entender las ventajas de una lucha conjunta con la que apuntalar su presencia y reclamar su espacio. [Nota de MV.]

I7 Para ello he analizado la representación de la identidad femenina en el cómic y su rescate desde la autoría femenina en diversos textos ponencias y colaboraciones a partir de la investigación realizada para mi tesis doctoral, con el mismo propósito que me mueve desde mi primer artículo. Véase "Mujer objeto y sujeto del cómic", Totem i977. [Nota de MV.]

\section{OBRAS CITADAS}

Moix, TERENCi. Historia social del cómic. 1968. Barcelona: Bruguera, 2007. 
NASH, MARY. Dones en transició. De la resistència política a la legitimitat feminista: les dones en la Barcelona de la Transició. Barcelona: Ajuntament de Barcelona, 2007.

VILA MIGUELOA, MARÍA DEL CARMEN (MARIKA). "Las autoras españolas en el boom del cómic adulto. La mordaza patriarcal y el silencio roto." Del Boom al Crack. La explosión del cómic adulto en España (1977-1995). Ed. Gerardo Vilches. Barcelona: Diminuta Editorial, 2018. 203-227.

- El cos okupat. Iconografies del cos femení com a espai de la transgresió masculina en el còmic. Tesis doctoral. Universitat de Barcelona, Facultat de Filologia, 2017.

-. Derrumbando estereotipos. La subjetividad femenina en el cómic. Gijón: Semana Negra de Gijón, 2018.

—. "Mujer objeto y sujeto del cómic." Totem. Especial Mujeres. 1977· 33³4.

Zanatt A, SARA. “Corpi di donne: oggetti o soggetti?” Le donne del fumetto. L'altra metà dei comics italiani: temi, autrici, personaggi al femminile. Ed. Sara Zanatta. Latina: Tunuè, 2009. 57-117. 